\title{
Luminescence Spectroscopy Applied to a Study of the Curing Process of Diglycidyl-Ether of Bisphenol-A (DGEBA)
}

\author{
Rita de Cássia Mendonça Sales, Deborah Dibbern Brunelli* \\ Department of Chemistry, Instituto Tecnológico de Aeronáutica, \\ Praça Marechal Eduardo Gomes, 50, Vila das Acácias \\ 12228-900 São José dos Campos - SP, Brazil
}

Received: November 18, 2004; Revised: March 22, 2005

\begin{abstract}
This work involved the application of luminescence spectroscopy under steady-state conditions to study the curing process of the epoxy resin diglycidyl-ether of bisphenol-A (DGEBA) using the curing agents 4,4'diaminodiphenylmethane (DDM) and 4,4'-diaminodiphenylsulfone (DDS). Two fluorescence methods were employed: the intrinsic method related to the polymeric matrix and the extrinsic method, using the molecular probe 9-anthroic acid (9-AA). Stoichiometric mixtures, with and without 9-AA, were heated to $120{ }^{\circ} \mathrm{C}$ at a $5{ }^{\circ} \mathrm{C} / \mathrm{min}$ heating rate. These samples were then cured at $120^{\circ} \mathrm{C}$ for a further 2 hours and allowed to cool to room temperature for 20 minutes. The results obtained by the two methods indicate that the cross-linking reaction can be monitored by analyzing the spectral changes of the emission bands of DGEBA, curing agents and 9-AA.
\end{abstract}

Keywords: composites, intrinsic luminescence, extrinsic luminescence, heat treatment

\section{Introduction}

High performance composites of fiber-reinforced organic resin are increasingly used in the aeronautics and space industries. Characterization of the extent of cure and water uptake in polymers and composites before, during and after the manufacturing process is extremely important to improve their mechanical properties ${ }^{1}$.

Several methods such as differential scanning calorimetry $(\mathrm{DSC})^{2-4}$, temperature modulated differential scanning calorimetry (TMDSC) $)^{5,6}$, dielectric analysis (DEA), dynamic-mechanical analysis (DMA) $)^{3,7-9}$ and infrared spectroscopy (FTIR) ${ }^{10,11}$ have been used to monitor the curing process of resins and composites. However, thermal and dynamic methodologies are not applicable on-line and are destructive analytical techniques. Although infrared absorption can follow primary changes in chemical reactions, since epoxy cure monitoring is possible through absorption in the primary amine region at $3367 \mathrm{~cm}^{-1}$, it is not useful for monitoring opaque or black samples. In contrast to other techniques, luminescence spectroscopy is both sensitive and selective, and can be used for the nondestructive analysis of polymerization processes both on- and off-line.

Luminescence spectroscopy has been used to study the curing process and the water uptake of polymeric resins and composites. It has been reported that the spectral shifts of the intrinsic fluorescence of samples can be used to determine the extent of the cure in epoxy composites cured with a commonly used aromatic diamine ${ }^{12}$.

The technique's high sensitivity also allows for studies of the glass fiber-matrix interface, using suitable extrinsic fluorophores or molecular probes, which present different photophysical behaviors when located in the polymer matrix or on glass fiber surfaces ${ }^{13}$.

Hakala et al. ${ }^{14}$ monitored the curing process and shelf life of the epoxy-anhydride system, using the luminescence of intramolecular charge-transfer compounds. These researchers observed that the probes displayed blue or red shifts upon polymerization at different temperatures.

Strehmel et al. ${ }^{15}$ studied a charge transfer probe - the Tetraethylene glycol diacrylate (TEGDA) system, during the cure process. They noted the appearance of a new band in the blue region, while the emission in the red region decreased due to the cross-linking reaction involved in changes in the free volume of the polymeric matrix.

The purpose of this work is to study the influence of the heat treatment of stoichiometric mixtures of DGEBA/DDM and DGEBA/ DDS through intrinsic and extrinsic fluorescence methods, using the 9-anthroic acid (9-AA) molecular probe.

\section{Materials and Methods}

\subsection{Preparation of the samples}

The following solutions were prepared: $1 \times 10^{-2} \mathrm{~mol} / \mathrm{L}$ DGEBA (diglycidyl-ether of bisphenol-A-D.E.R.331 - Dow Chemical Products Ltd.) in n-butanol (Merck) and $1 \times 10^{-3}, 1 \times 10^{-4}$, $1 \times 10^{-5} \mathrm{~mol} / \mathrm{L}$ 9-AA (9-anthroic acid - Aldrich Chemical Company, Inc.) in DGEBA.

The curing agents DDS (4,4'-diaminodiphenylsulfone - HT 976 - Ciba Geigy Chemical S/A) and DDM (4,4'-diaminodiphenylmethane - D.E.H.50 - Dow Chemical Products Ltd.) were used to prepare stoichiometric mixtures of DGEBA/DDS $(10: 3 \mathrm{~m} / \mathrm{m})$ and DGEBA/ DDM $(10: 2.7 \mathrm{~m} / \mathrm{m})$ with and without 9-AA. The stoichiometric mixtures, with and without 9-AA, were heated to $120^{\circ} \mathrm{C}$ at a rate of $5{ }^{\circ} \mathrm{C} /$ min using a woven EDG3000 - EDGCON3P. These samples were then heat-treated at $120{ }^{\circ} \mathrm{C}$ for another 2 hours and allowed to cool to room temperature for 20 minutes (Figure 1).

\subsection{Fluorescence spectra}

Fluorescence spectra were measured using a steady-state luminescence spectrometer (FS920 - Edinburgh Analytical Instruments) in the photo-counting mode, equipped with a xenon arc lamp $450 \mathrm{~W}$ (Osram Co.) and double holographic grating monochromators of excitation and emission (Czerny-Turner configurations).

The fluorescence spectra of the solid samples were acquired through front-face illumination. The excitation wavelengths were carefully chosen, since the epoxy resin presented many emission 
bands in the 290-380 $\mathrm{nm}$ range. The fluorescence spectra of DGEBA, curing agents (DDM and DDS) and 9-AA were measured in the excitation wavelengths of 313,370 and $395 \mathrm{~nm}$, respectively.

\section{Results and Discussion}

\subsection{Intrinsic fluorescence method}

The intrinsic luminescence of the resin was studied by investigating the photophysical behavior of $1 \times 10^{-2} \mathrm{~mol} / \mathrm{L}$ DGEBA in n-butanol solution (Figure 2). The excitation spectra showed a broad band with its maximum at $294 \mathrm{~nm}$ and two shoulders with maxima at 310 and $320 \mathrm{~nm}$ (Figure 2.1). The excitation wavelengths at 290 and $310 \mathrm{~nm}$ were used to obtain the emission spectra. Two unstructured emission bands with maximum wavelengths at 313 (Figure 2.2.) and $345 \mathrm{~nm}$ (Figure 2.3) were found to be dependent on the excitation wavelength.

Some fluorescent probes whose chromophores contain both an electron donor and an electron acceptor via their conjugation through an aromatic ring can form intramolecular charge transfer (ICT) complexes. Upon excitation, the bond between the donor and the acceptor

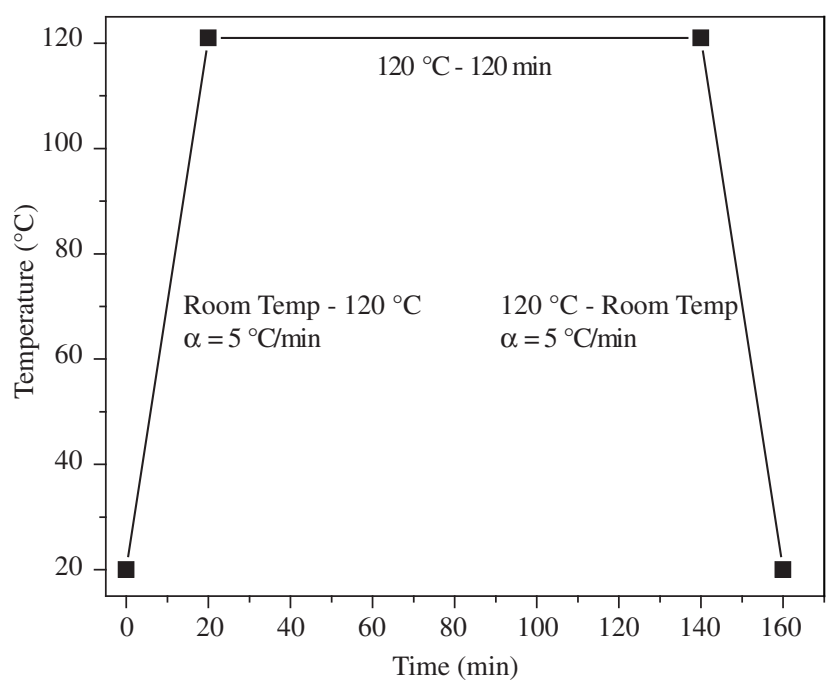

Figure 1. Heat treatment of the DGEBA/DDS and DGEBA/DDM samples.

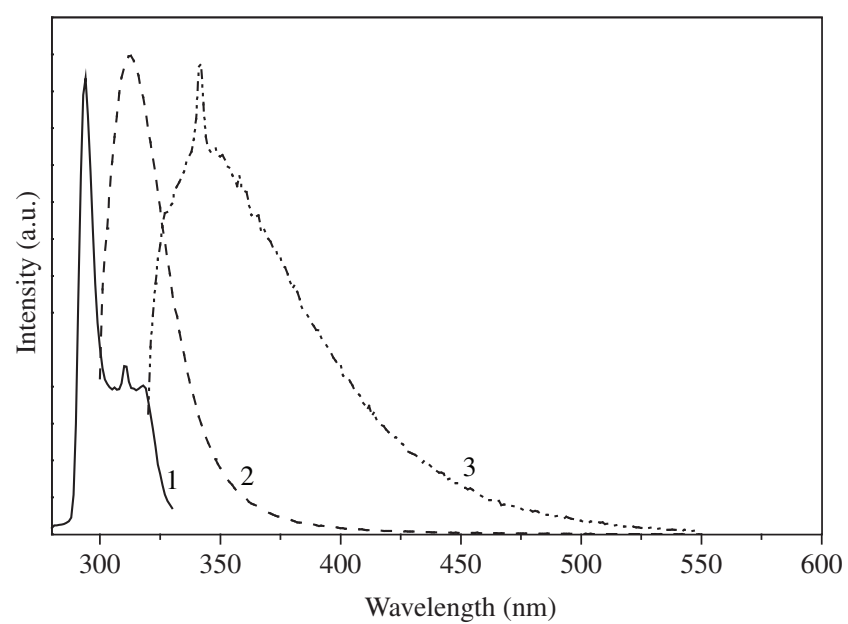

Figure 2. Excitation and fluorescence spectra of DGEBA in n-butanol $\left.\left(1 \times 10^{-2} \mathrm{~mol} / \mathrm{L}\right): 1\right)$ excitation monitored at $345 \mathrm{~nm}$ and fluorescence excited at 2) $290 \mathrm{~nm}$ and (3) $310 \mathrm{~nm}$. is twisted within the singlet state lifetime due to intramolecular charge separation. As a result, such molecules emit from two excited singlet states, one coplanar and the other twisted, and typically exhibit dual fluorescence emissions ${ }^{16,17}$. Since the DGEBA structure (Figure 3) contains both groups linked by aromatic rings, it may suggest the formation of ICT complexes in the macromolecule, which would explain the two emission bands ${ }^{17}$.

Figure 4 shows the excitation spectra of the DGEBA and DDM mixture before and after the 2 hours $\left(5^{\circ} \mathrm{C} / \mathrm{min}\right.$ heating rate $) 120^{\circ} \mathrm{C}$ heat treatment. The excitation spectra of the DGEBA and DDM mixture before the heat treatment show a band at $329 \mathrm{~nm}$ (Figure 4.1) relating to the DGEBA and a band with 336 and $359 \mathrm{~nm}$ maxima (Figure 4.3) assigned to the DDM. After the heat treatment, the excitation spectra of the DGEBA and DDM mixture show an increase in the relative intensity of the band at $331 \mathrm{~nm}$ (Figure 4.2), which was assigned to the DGEBA. A significant red shift of the excitation maximum (Figure 4.4) to $395 \mathrm{~nm}$ was observed and attributed to DDM emission.

Figure 5 shows the emission spectra of the DGEBA and DDM mixture before and after the heat treatment at $120^{\circ} \mathrm{C}$ for 2 hours $\left(5^{\circ} \mathrm{C} / \mathrm{min}\right.$ heating rate). The fluorescence spectra of DGEBA and DDM mixture, before the heat treatment, show a weak band at $350 \mathrm{~nm}$ (Figure 5.1) associated with the DGEBA emission, as shown in Figure 2.2, and a weak band at $428 \mathrm{~nm}$ (Figure 5.2) attributed to the DDM emission.

After the heat treatment, the fluorescence spectra of the DGEBA and DDM mixture revealed an increase in the band's relative intensity at $351 \mathrm{~nm}$ (Figure 5.3), which was assigned to the DGEBA emission. A significant red shift to $475 \mathrm{~nm}$ occurred in the emission maximum (Figure 5.4), attributed to DDM emission. The DDM curing agent contains primary amines and the curing reaction consists of the conversion of these groups into secondary and tertiary groups. The spectral shift of the emission band has to do with the conversion of primary amines into secondary and tertiary amines during the curing process ${ }^{18}$. Dang and Sung ${ }^{19,20}$ observed a similar behavior using the molecular probe diaminoazobenzene (DAA), which presented a quantum yield increase and a red shift of the absorption maxima pursuant to the conversion of primary into tertiary amines, as well greater electron-donating ability. Therefore, the same attribution possibly holds true for DDM emission. Based on this photophysical behavior, one can conclude that the intrinsic fluorescence of DGEBA and DDM can also be used to monitor their curing reaction, since spectral changes in DDM fluorescence occurred.

The excitation spectra of he DGEBA/DDS mixture before the curing process (Figure 6.1) show a weak broad band at $355 \mathrm{~nm}$. This band was also observed by Sung and Paik ${ }^{19}$. After the DGEBA/DDS mixture was cured, a red shift occurred in the excitation band (Figure 6.2) and the relative intensity of the band at $365 \mathrm{~nm}$ increased due to a conversion of primary amines into secondary and tertiary amines ${ }^{1,12,19,20}$.

Figure 6 shows the fluorescence spectra of the DGEBA and DDS mixture before (Figure 6.3) and after the heat treatment (Figure 6.4). The excitation wavelength was fixed at $350 \mathrm{~nm}$, since emission spectra are independent of excitation wavelengths. The mixture not heat-treated displayed an emission band at $382 \mathrm{~nm}$. Even so, a red shift of the emission band to $395 \mathrm{~nm}$ occurred after the heat treatment. This band was attributed to DDS fluorescence. The curing reaction of epoxy-diamine monitored in situ using intrinsic fluorescence of DGEBA with DDS reportedly displays a spectral shift in both absorption and fluorescence spectra in response to the conversion of primary to tertiary amine ${ }^{21,22}$.

Both the DDM and DDS curing agents (Figure 7) showed a red shift in their emission maxima after heat treatment, but this effect was more pronounced in the DDM fluorescence. It has been reported 


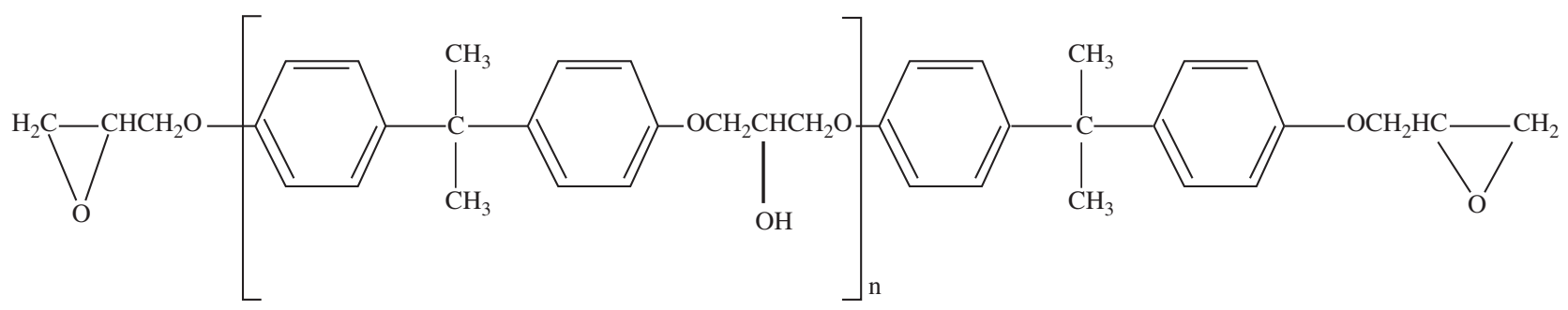

Diglycidyl ether of Bisphenol-A

Figure 3. Chemical structure of DGEBA epoxy resin.

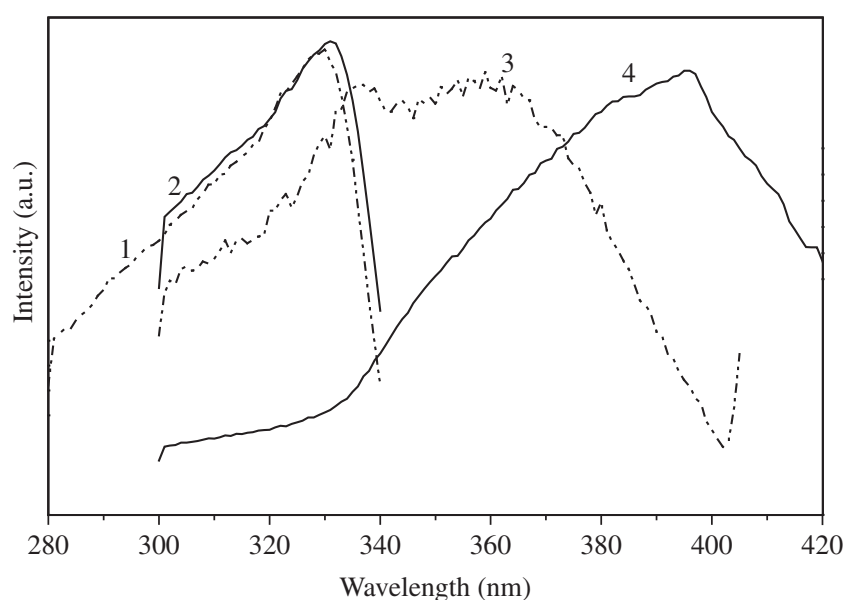

Figure 4. Excitation spectra of the stoichiometric DGEBA/DDM mixture (100:27 m/m) monitored at: 1) and 2) $350 \mathrm{~nm}$; 3) $415 \mathrm{~nm}$ and 4) $452 \mathrm{~nm}$. Dashed lines refer to DGEBA/DDM mixture before heat-treating; full lines correspond to the DGEBA/DDM mixture after heat-treating at $120{ }^{\circ} \mathrm{C}$ for $2 \mathrm{~h}\left(5^{\circ} \mathrm{C} / \mathrm{min}\right.$ heating rate).

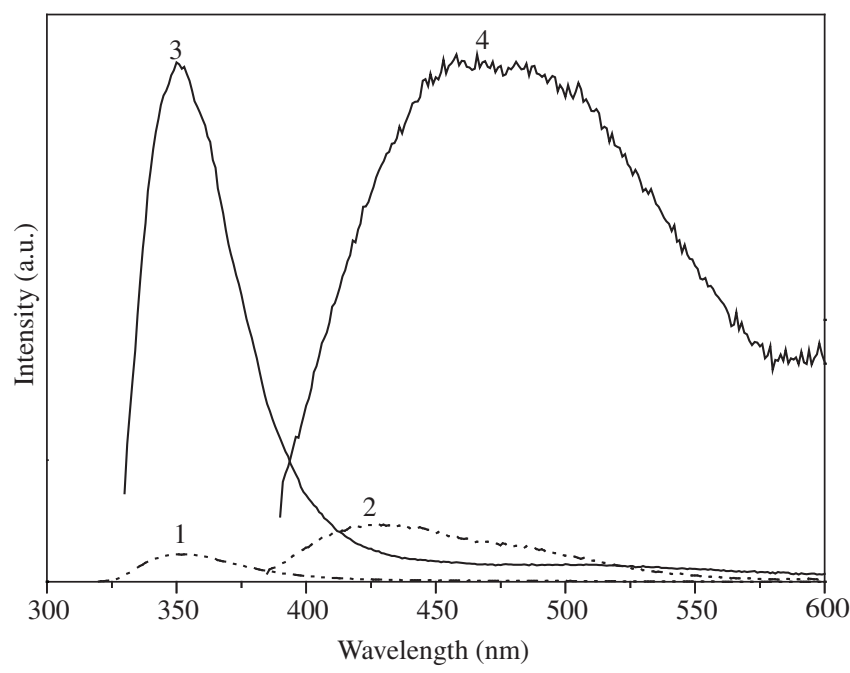

Figure 5. Fluorescence spectra of the stoichiometric DGEBA/DDM mixture $(100: 27 \mathrm{~m} / \mathrm{m})$ excited at: 1) and 3) $313 \mathrm{~nm}$; 2) and 4) $370 \mathrm{~nm}$. Dashed lines refer to the DGEBA/DDM mixture before heat-treating; full lines refer to the DGEBA/DDM mixture after heat-treating at $120^{\circ} \mathrm{C}$ for $2 \mathrm{~h}\left(5^{\circ} \mathrm{C} / \mathrm{min}\right.$ heating rate).

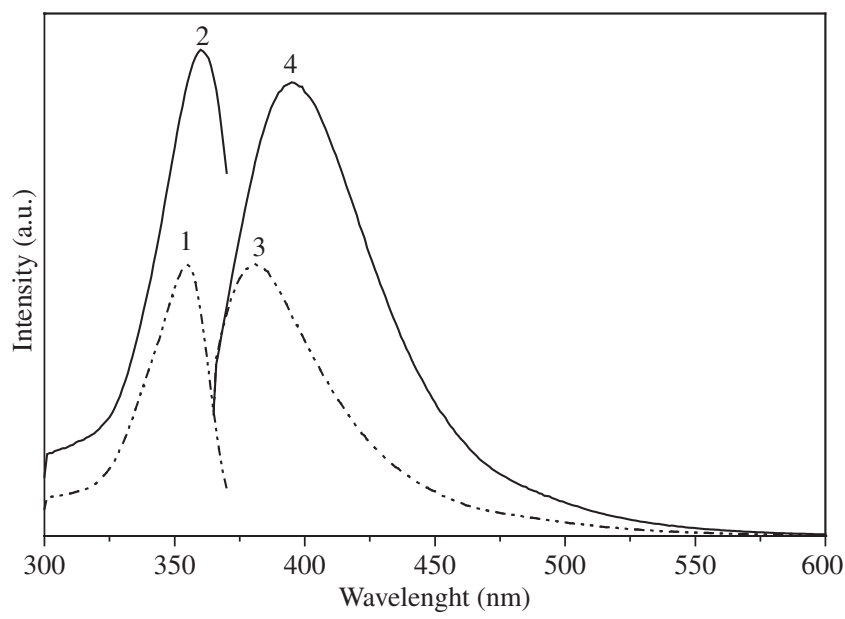

Figure 6. Excitation and fluorescence spectra of the stoichiometric DGEBA/DDS mixture 100:30 m/m: excitation monitored at 1) $385 \mathrm{~nm}$ and 2) $393 \mathrm{~nm}$ and fluorescence excited at 3) and 4) $350 \mathrm{~nm}$. Dashed lines refer to the DGEBA/DDM/9AA mixture before heat-treating; full lines refer to the DGEBA/DDM/9AA mixture after heat-treating at $120^{\circ} \mathrm{C}$ for $2 \mathrm{~h}\left(5^{\circ} \mathrm{C} / \mathrm{min}\right.$ heating rate).

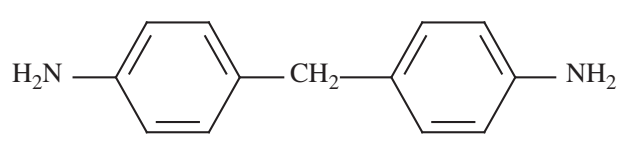

(a)

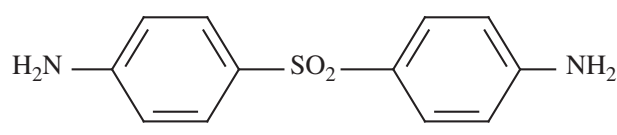

(b)

Figure 7. Chemical structure of curing agents: a) DDM; b) DDS.

that the $\mathrm{SO}_{2}$ functional group of the DDS structure exerts a delaying action on the reactivity of the amine functions since it is a highly electron-attracting group, which deactivates benzene rings and decreases the basicity of diamine. This effect is further enhanced by para-substitution, since the electron transfer from $\mathrm{NH}_{2}$ to $\mathrm{SO}_{2}$ is easier. In contrast, the $\mathrm{CH} 2$ group in DDM is an electron-donating group that stabilizes the benzene ring. Therefore, DDM is more reactive 
than DDS ${ }^{22.23}$. The net result of this behavior is that DDM reacts at a faster rate than DDS, and the degree of curing is probably highest in the DGEBA and DDM mixture.

\subsection{Extrinsic fluorescence method}

This sub-section discusses the photophysical behavior of 9-AA which is dependent on the curing reaction of the polymeric matrix. This required an analysis of the influence of the molecular probe concentration in DGEBA solutions.

Figure 8 depicts the emission spectra of 9-AA in DGEBA in concentrations of $1 \times 10^{-5}, 1 \times 10^{-4}$ and $1 \times 10^{-3} \mathrm{~mol} / \mathrm{L}$. The fluorescence spectrum of $1 \times 10^{-5} \mathrm{~mol} / \mathrm{L}$ 9-AA in DGEBA solution (Figure 8.1) shows a vibronically structured band that is quite similar to the anthracene emission band. Previous studies have shown that the carboxylic ion of the 9-AA ionized form remains in the perpendicular plane in relation to the anthracenic ring in the excited electronic state, so the net result is an anthracene-like emission ${ }^{24}$. Therefore, it can be concluded that the structured emission band was attributable to the ionized form of 9-AA. The decreased intensity of the peak at $390 \mathrm{~nm}$ resulted from reabsorption caused by the spectral overlapping of both absorption and emission bands.

As the concentration increased, a broad band appeared at $448 \mathrm{~nm}$ superimposed over the structured one (Figure 8.2), which was attributed to the protonated form of 9-AA (Figure 9). According to the above discussion, the protonated form presents a rotation of the carboxyl group in the excited state into a position approaching co-planarity with the anthracene ring. This can cause a significant resonance interaction between the carboxyl groups and change the nature of the excited state, resulting in the broad emission band.

A further increase in the concentration of the solution was found to relate to a red shift of the unstructured band (Figure 8.3) at $462 \mathrm{~nm}$. This band was attributed to the formation of the hydrogen-bonded dimer of the 9-AA protonated form ${ }^{25.26}$.

Figure 10 shows the excitation and fluorescence spectra of a mixture of DGEBA and DDM containing the 9-AA fluorescent probe before and after heat treatment. The excitation spectra of the mixture before heat treatment (Figure 10.1) show a broad band with a maximum at $363 \mathrm{~nm}$ and a shoulder at $318 \mathrm{~nm}$. After heat-treating (Figure 10.2), the shoulder disappeared and a red shift of the band was observed with a maximum at $404 \mathrm{~nm}$. Momiji ${ }^{26}$ observed the same $10^{-4} \mathrm{~mol} / \mathrm{L} 9 \mathrm{AA}$ band in neutral solutions of $0.4 \mathrm{~mol} / \mathrm{L} \mathrm{SDS}$, and attributed it to a dimeric form of 9AA.

The emission spectra of the DGEBA/DDM/9-AA mixture before heat-treating show two superimposed bands with emission maxima at 457 and $481 \mathrm{~nm}$ (Figure 10.3), which were attributed to the equilibrium of the dimer and protonated forms of 9-AA. It was found that both emissions were red shifted in relation to 9-AA in concentrated DGEBA solutions (Figure 8.2). This spectral shift probably resulted from changes in the average polarity, since DDM curing agent was added to the resin.

After the heat treatment, a spectral shift of the emission band occurred at $481 \mathrm{~nm}\left(\lambda_{\text {exc }}=395 \mathrm{~nm}\right)$ (Figure 10.4), assigned to the fluorescence of 9-AA, suggesting that this band related to the dimeric form of 9-AA. The presence of dimers in the polymeric matrix indicates the increase of the local concentration of 9-AA. The presence of chemical cross-links in a polymer sample reportedly decreases its specific volume, i.e., the free volume is reduced ${ }^{27}$. Hence, it can be concluded that the extrinsic fluorescence of the molecular probe serves to monitor the curing reaction as effectively as the intrinsic method.

Figure 11 shows the excitation spectra of the 9-AA molecular probe dissolved in the DGEBA/DDS mixture before and after heat treatment, revealing a structured band before the heat treatment with maxima at 367 and $387 \mathrm{~nm}$ (Figure 11.1). After the heat treatment (Figure 11.2), the maximum at $387 \mathrm{~nm}$ disappeared and the band shifted to blue.

As can be seen in the Figure, 9-AA dissolved in the DGEBA/DDS mixture displayed emission bands at $445 \mathrm{~nm}$ (Figure 11.3) before and $410 \mathrm{~nm}$ (Figure 11.4) after the heat treatment. It should be noted that the emission maximum shifted to blue as the sample was heated,

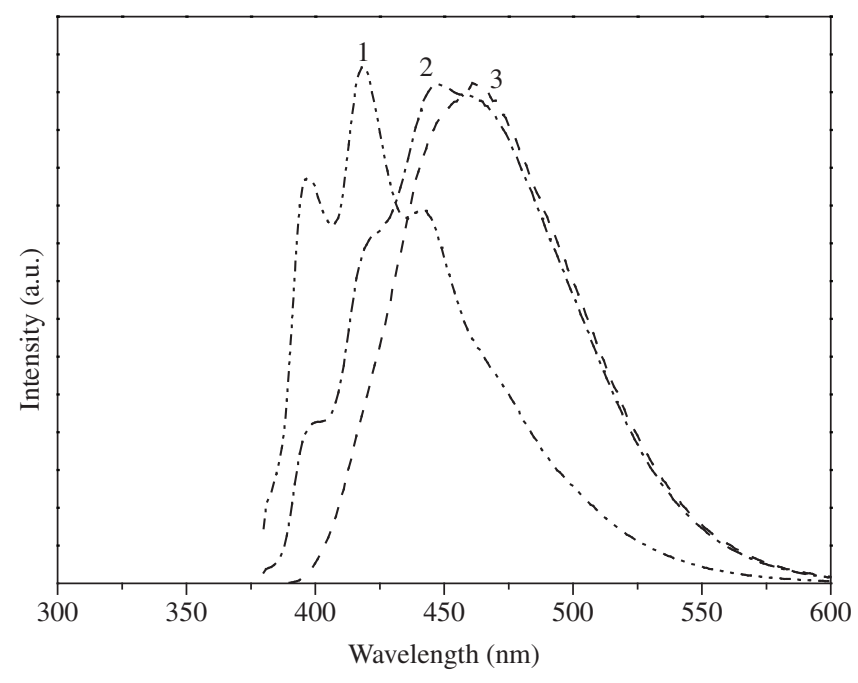

Figure 8. Fluorescence spectra of 9-AA in DGEBA solutions in concentrations $(\mathrm{mol} / \mathrm{L})$ of 1$\left.\left.) 1 \times 10^{-5} ; 2\right) 1 \times 10^{-4} ; 3\right) 1 \times 10^{-3}\left(\lambda_{\text {exc }}=370 \mathrm{~nm}\right)$.<smiles>O=C([O-])c1c2ccccc2cc2cc3ccccc3c(C(=O)O)c12</smiles>

Figure 9. Acid-basic equilibrium of 9-AA in protic solvents.

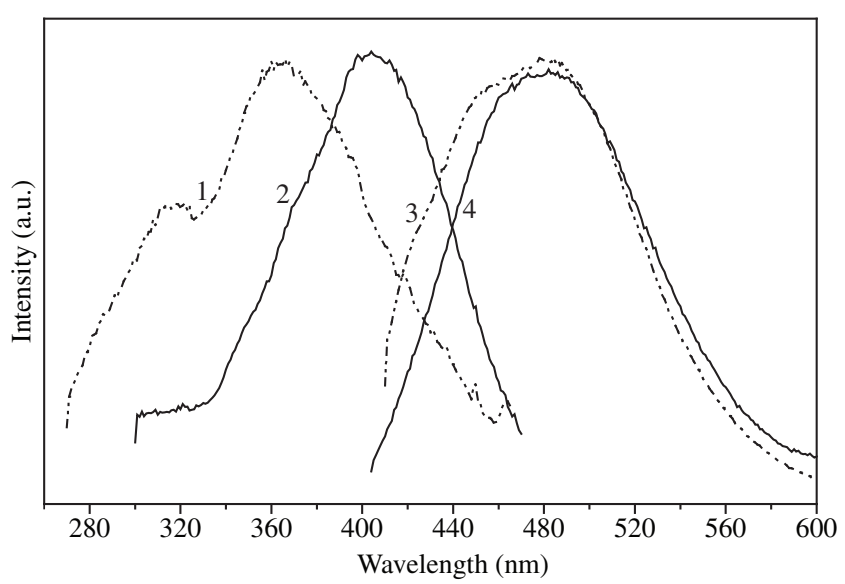

Figure 10. Excitation and fluorescence spectra of the DGEBA/DDM/9-AA mixture: excitation monitored at 1) $480 \mathrm{~nm}$ and 2) $486 \mathrm{~nm}$, fluorescence excited at 3) and 4) $395 \mathrm{~nm}$. Dashed lines refer to the DGEBA/DDM/9AA mixture before heat-treating; full lines refer to the DGEBA/DDM/9AA mixture after heat-treating at $120^{\circ} \mathrm{C}$ for $2 \mathrm{~h}\left(5^{\circ} \mathrm{C} / \mathrm{min}\right.$ heating rate). 


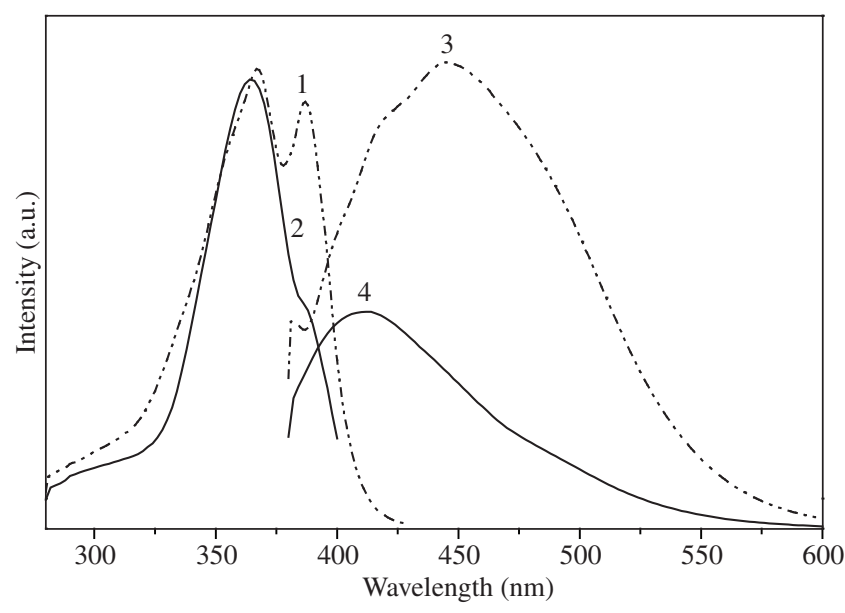

Figure 11. Excitation and fluorescence spectra of the DGEBA/DDS/9-AA mixture: excitation monitored at 1) $445 \mathrm{~nm}$ and 2) $415 \mathrm{~nm}$, fluorescence excited at 3) and 4) $365 \mathrm{~nm}$. Dashed lines refer to DGEBA/DDM/9AA mixture before heat-treating; full lines refer to the DGEBA/DDM/9AA mixture after heat-treating at $120^{\circ} \mathrm{C}$ for $2 \mathrm{~h}\left(5^{\circ} \mathrm{C} / \mathrm{min}\right.$ heating rate $)$.

possibly due to an equilibrium displacement from the dimeric to the protonated form of 9-AA.

The photophysical behavior of 9-AA in the DGEBA/DDM and DGEBA/DDS mixtures after the heat treatment was quite different, for the dimeric form was detected in the former and the protonated form in the latter mixture. Based on the intrinsic fluorescence method, we propose that DDM reacts at a faster rate than DDS. The results obtained through the extrinsic fluorescence method indicate that the delay in the curing reaction of DGEBA with DDS may favor the diffusion of the molecular probe through the polymeric matrix, reducing its local concentration and displacing its equilibrium, tending toward the formation of the protonated species of 9-AA. These results suggest that the curing reaction can also be monitored by the extrinsic method.

\section{Conclusions}

The results obtained through the intrinsic fluorescence method indicate that the cross-linking reaction can be monitored based on an analysis of the red shift of the DGEBA emission bands and the curing agents. The spectral changes in DDM and DDS fluorescence relate to the conversion of primary amines into secondary and tertiary amines. Nonetheless, this effect was more pronounced in the DGEBA/DDM mixture than in the DGEBA/DDS mixture due to the higher reactivity of DDM during heat treatment.

The extrinsic fluorescence method showed that the photophysical behavior of 9-AA in the DGEBA/DDM and DGEBA/DDS mixtures after heat treatment was quite different, for the dimeric form was detected in the former mixture and the protonated form in the latter. The presence of the dimeric form in the DGEBA/DDM mixture indicated that the cross-linking reaction reduced the free volume and increased the concentration of 9-AA. On the other hand, the presence of the protonated form in the DGEBA/DDS mixture after the heat treatment indicated that it may have diffused through the polymeric matrix, since the DDS curing agent was less reactive.

Finally, it was concluded that fluorescence spectroscopy is sensitive and suitable in studies of the curing process by both the intrinsic and the extrinsic methods.

\section{Acknowledgments}

The authors gratefully acknowledge the financial support of this work by FAPESP (Brazil). R. C. M. S. is indebted to CAPES (Brazil) for a fellowship.

\section{References}

1. Sung CSP, Sung NH. Fluorescence characterization of cure and water uptake in polymers and composites. Materials Science and Engineering A. 1993; 162(1-2): 241-247.

2. Zvertkov VL. Comparative DSC kinetics of the reaction of DGEBA with aromatic diamines. I. Non-isothermal kinetic study of the reaction of DGEBA with m-phenylene diamine. Polymer. 2001; 42(16): 66876697.

3. Ramis X, Cadenato A., Morancho JM, Salla JM. Curing of a thermosetting powder coating by means of DMTA, TMA and DSC. Polymer. 2003; 44(7): 2067-2079.

4. Montserrat S, Cima I. Isothermal curing of an epoxy resin by alternating differential scanning calorimetry. Thermochimica Acta. 1999; 330(1-2): 189-200.

5. Montserrat S, Martín JG. Non-isothermal curing of a diepoxide-cycloaliphatic diamine system by temperature modulated differential scanning calorimetry. Thermochimica Acta. 2002; 388(1-2): 343-354.

6. Li C, Potter K, Wisnom MR, Stringer G. In-situ measurement of chemical shrinkage of MY750 epoxy resin by a novel gravimetric method. Composites Science and Technology. 2003; 63(1): 1-10.

7. Van-De-Velde JG, Marsh RDL, Wetton RE. Theory and application of dynamic mechanical thermal analysis. Thermochimica Acta. 1991; 175(1): $1-11$.

8. Oulevey F, Burnham NA, Gremaud G, Kulik AJ, Pollock HM, Hammiche A, et al. Dynamic mechanical analysis at the submicron scale. Polymer. 2000; 41(8): 3087-3092.

9. Kim HG, Lee DG. Dielectric cure monitoring for glass/polyester prepreg composites. Composite Structure. 2002; 57(1-4): 91-99.

10. Benito JG. The nature of the structural gradient in epoxy curing at a glass/fiber epoxy matrix interface using FT-IR imaging. Journal of Colloid and Interface Science. 2003; 267(2): 326-332.

11. Monney L, Belali R, Vebrel J, Dubois C, Chambaudet A. et al. Photochemical degradation study of an epoxy material by IR-ATR spectroscopy. Polymer Degradation and Stability. 1998; 62(2): 353-359.

12. Sung CSP, Yu JW. Interphase cure characterization in epoxy composites by fluorescence technique. Journal of Applied Polymer Science. 1997; 63(13):1769-1775.

13. Baselga J, Pozuelo J. Curing of polymer matrix composites. Fluorescence study of dansyl fluorophore labeled to glass fibers and DGEBA-ethylenediamine epoxy resin. Journal of Materials Processing Technology. 2003; 143-144: 332-336.

14. Hakala K, Vatanparast R, Li S, Peinado C, Bosh P, Catalina F, et al. Monitoring of curing process and shelf life of the epoxy-anhydride system with TICT compounds by the fluorescence technique. Macromolecules. 2000; 33(16): 5954-5959.

15. Strehmel B, Malpert JH, Sarker AM, Neckers D C. New intramolecular fluorescence probes that monitor photoinduced radical and cationic crosslinking. Macromolecules. 1999; 32(22): 7476-7482.

16. Neckers DC, Bao R, Song JC, Wang ZJ. Fluorescence probes for monitoring polymerization processes. Journal of Polymer Science. Part B: Polymer Physics. 1996; 34(2): 325-333.

17. Birks JB. Photophysics of Aromatic Molecules. revised ed. London: John Wiley \& Sons; 1995.

18. Strehmel B, Strehmel V, Younes M. Fluorescence probes for investigation of epoxy systems and monitoring of crosslinking processes. Journal of Polymer Science: Part B: Polymer Physics. 1999; 37(13): 1367-1386.

19. Sung NH; Paik HJ. Fiberoptic intrinsic fluorescence for in-situ cure monitoring of amine cured epoxy and composites. Polymer Engineering 
and Science. 1994; 34(12): 1025-1032.

20. Dang W, Sung NH. In-situ cure monitoring of diamine cured epoxy by fiberoptic fluorometry using extrinsic reactive fluorophore. Polymer Engineering and Science. 1994; 34(9): 707-715.

21. Baselga J, Martin O. The use of 9- anthroic acid and new amide derivatives to monitorize curing of epoxy resins. Journal of Materials Processing Technology. 2003; 143-144: 851-855.

22. Boey FYC, Yap BH. Microwave curing of an epoxy-amine system: effect of curing agent on the glass-transition temperature. Polymer Testing. 2001; 20(8): 837-845.

23. Boey FYC, Yap BH, Chia L. Microwave curing of epoxy-amine system: effect of curing agent on the rate enhancement. Polymer Testing. 1999;
18(2): 93-109.

24. Suzuki S, Fujii T, Yoshiike N. Polarization of the excimer-type transition in 9-anthroic acid. Chemical Physics Letters. 1979; 62(2): 287-290.

25. Suzuki S, Fujii T, Yoshiike N, Komatsu S, Toshido I. Absorption and fluorescence spectra of anthracenecarboxylic acids. I. 9-anthroic acid and formation of excimer. Bulletin of the Chemical Society of Japan. 1978; 51(9): 2460-2466

26. Momiji I, Yoza C, Matsui K. Fluorescence spectra of 9- anthracenecarboxylic acid in heterogeneous environments. Journal of Physical Chemistry B. 2000; 104(7): 1552-1555.

27. Young RJ and Lovell PA. Introduction to Polymers. revised ed. London: Chapman \& Hall; 1991 